\title{
ARTICLE OPEN \\ Computer decision support systems for asthma: a systematic review
}

\author{
Patricia Matui ${ }^{1}$, Jeremy C Wyatt ${ }^{2}$, Hilary Pinnock ${ }^{1}$, Aziz Sheikh ${ }^{1}$ and Susannah McLean ${ }^{1}$
}

BACKGROUND: Increasing use of electronic health records offers the potential to incorporate computer decision support systems (CDSSs) to prompt evidence-based actions within routine consultations.

AIM: To synthesise the evidence for the use of CDSSs by professionals managing people with asthma.

MATERIALS AND METHODS: We systematically searched Medline, Embase, Health Technology Assessment, Cochrane and Inspec databases (1990 to April 2012, no language restrictions) for trials, and four online repositories for unpublished studies. We also wrote to authors. Eligible studies were randomised controlled trials of CDSSs supporting professional management of asthma. Studies were appraised (Cochrane Risk of Bias Tool) and findings synthesised narratively.

RESULTS: A total of 5787 articles were screened, and eight trials were found eligible, with six at high risk of bias. Overall, CDSSs for professionals were ineffective. Usage of the systems was generally low: in the only trial at low risk of bias the CDSS was not used at all. When a CDSS was used, compliance with the advice offered was also low. However, if actually used, CDSSs could result in closer guideline adherence (improve investigating, prescribing and issuing of action plans) and could improve some clinical outcomes. The study at moderate risk of bias showed increased prescribing of inhaled steroids.

CONCLUSIONS: The current generation of CDSSs is unlikely to result in improvements in outcomes for patients with asthma because they are rarely used and the advice is not followed. Future decision support systems need to align better with professional workflows so that pertinent and timely advice is easily accessible within the consultation.

npj Primary Care Respiratory Medicine (2014) 24, Article number: 14005; doi:10.1038/npjpcrm.2014.5; published online 20 May 2014

\section{INTRODUCTION}

The Global Initiative for Asthma estimates that 300 million people worldwide have asthma. ${ }^{1}$ Prevalence rates as high as $32 \%$ have been recorded in the United Kingdom and Australia, ${ }^{2}$ and the prevalence is increasing in many parts of the world. ${ }^{3-5}$ Despite evidence-based guidelines, ${ }^{1,6-9}$ there is consistent evidence that asthma is suboptimally controlled, resulting in unnecessary morbidity, loss of school and workdays, and high costs for countries. $^{9-11}$ There are 250,000 asthma-related deaths each year. ${ }^{1}$

There are many reasons why guidelines are poorly implemented, including physician's lack of knowledge or inertia of practice. ${ }^{12,13}$ As electronic health records are now the norm in many parts of the world, ${ }^{14,15}$ it is feasible to provide professionals with computer decision support systems (CDSSs) to prompt evidence-based actions within routine consultations, potentially improving professional adherence to guidelines.

Our systematic review aimed to synthesise the evidence for the use of CDSSs by professionals managing people with asthma. We were primarily interested in the effectiveness of CDSSs in improving patient outcomes, but also sought to investigate process measures of guideline adherence and practical usage of the system.

\section{MATERIALS AND METHODS}

Our protocol is registered with the PROSPERO international prospective register of systematic reviews (CRD 42012002412). We followed the methodology described in the Cochrane Handbook for Systematic Reviews of Interventions. ${ }^{16}$

\section{Inclusion criteria}

We used the PICOS (Participants, Intervention, Comparator, Outcomes, Study design) strategy for describing trials in which we were interested:

Participants. As this study is a review of the evidence, the study participants were de facto the health professionals using CDSSs who were caring for people with asthma-i.e., doctors, nurses and others (e.g., physiotherapists).

Intervention. We adopted Wyatt et al.'s definition of CDSs as 'active knowledge systems which use two or more items of patient data to generate case-specific advice. ${ }^{17}$ Haynes and Wilczynski similarly described such systems as 'information technology which matches characteristics of individual patients to a computerised knowledge base', with software algorithms generating patient-specific information in the form of recommendations. ${ }^{18}$ There are various levels of sophistication for CDSSs, from reminders to enter specific data, prescribe certain drugs/vaccines or provide an asthma action plan, to a system retrieving patient asthma information from an electronic health-care record and providing a critique on the intended clinical action. Systems were included if they used patient data to generate case-specific asthma advice. Systems relating only to the task of asthma diagnosis or those exclusively providing patients with support for self-management were excluded.

Comparator. The comparator was 'usual care', specifically without the use of a CDSS.

Outcomes. Our primary interest was in the impact of CDSSs on clinical asthma control. In line with recommended guidelines, ${ }^{19}$ we included outcomes that reflected current control (including asthma-related quality of life) and frequency of asthma exacerbations (including frequency of the

\footnotetext{
${ }^{1}$ Allergy and Respiratory Research and eHealth Research Groups, Centre for Population Health Sciences, The University of Edinburgh, Edinburgh, UK and ${ }^{2}$ Yorkshire Centre for Health Informatics, University of Leeds, Leeds, UK.

Correspondence: S McLean (susannah.mclean@ed.ac.uk)

Received 18 October 2013; revised 24 January 2014; accepted 31 January 2014
} 
general practitioner's asthma visits, emergency department asthma visits and asthma hospitalisations).

We were also interested in the process by which CDSSs might impact asthma control, both practical usage issues (e.g. the proportion of professionals who actually used the CDSS, the numbers of alerts issued and the impact on time within the consultation) as well as process measures reflecting enhanced guideline adherence (e.g. changes in treatment, in tests ordered and in the proportion of patients with asthma action plans).

Study design. All reports of randomised controlled trials of CDSSs used by health-care professionals for patients with asthma, in any language, published and unpublished, were eligible for inclusion. No other study designs were included.

\section{Information sources and search strategy}

We searched Medline, Embase, Cochrane Central Register of Controlled Trials, Health Technology Assessment and Inspec (engineering) databases from 1990 to April 2012 with the terms listed in Supplementary Appendix 1. We wrote to experts and authors of all included studies requesting additional relevant studies. We searched for ongoing and unpublished trials on the following websites: https://portal.nihr.ac.uk/ Pages/NRRArchive.aspx, www.clinicaltrials.gov, www.controlled-trials.com and www.anzctr.org.au.

\section{Study selection}

Two authors (PM and SM) independently screened titles and abstracts, assessing them against the inclusion criteria. The full text of each potentially eligible paper was reviewed by both authors to decide whether the study should be included. Disagreements were resolved by discussion and, if necessary, arbitration of a third researcher (HP, AS or JCW).

\section{Data collection and abstraction}

Using a piloted data extraction form, PM and SM independently extracted the following data from included trials: country, setting, funding, study design, health-care professionals, patient population, features of the CDSS intervention, description of the control group, outcome measures and any adverse effects. Extraction tables were compared, and discussed with a third researcher (HP, AS or JW) arbitrating in the event of unresolved disagreement.
Quality of reporting of trials

We assessed the risk of bias in each trial using the seven-criteria approach described in the Cochrane Handbook for Systematic Reviews of Interventions. ${ }^{16}$ Overall, each study was rated as follows: A: low risk of bias-no bias found; B: moderate risk of bias-one criterion for risk of bias; C: high risk of bias-more than one criterion for risk of bias.

\section{Synthesis of results}

We anticipated considerable heterogeneity in the populations studied, and in the interventions and the outcomes reported in the trials precluding meta-analysis of data. Instead, we planned to undertake a narrative synthesis based on our theoretical model of how such computer systems are expected to exert their effects (see Figure 1). The expectation is that, in a linked causal chain, CDSSs will impact process outcomes, which, in turn, will impact clinical outcomes. The theory underpinning their effectiveness is that relevant reminders and recommendations during a consultation will influence clinicians' behaviour and thereby improve guideline adherence as measured by process outcomes (e.g. more rational ordering of investigations, prescribing of treatment and use of asthma action plans). Implementation of evidence-based practices will consequently be measureable in clinical outcomes for asthma patients, such as fewer exacerbations, emergency department attendances and hospitalisations.

\section{RESULTS}

\section{Study selection}

Figure 2 is the PRISMA flow diagram. From 5,787 titles, eight studies were selected, ${ }^{20-27}$ seven in English and one in Spanish. ${ }^{26}$ One study had two reports. ${ }^{24,28}$ None of the experts we contacted identified any additional eligible studies. We found nine ongoing and eight unpublished trials (Supplementary Appendix 2).

We excluded a small group of studies from the early 1990s of computerised theophylline dose calculators because they addressed a specific problem in emergency care and have already been evaluated in a Cochrane review. ${ }^{29}$

\section{Study characteristics}

See Table 1 for details of study characteristics. Most studies were cluster randomised controlled trials ${ }^{20-26}$ in primary care in the UK $^{21,25}$ or the Netherlands. ${ }^{23,24}$ Two studies randomised practices to receive a CDSS for asthma prescribing or a system for angina or cholesterol prescribing. ${ }^{21,24}$ The practices providing data on

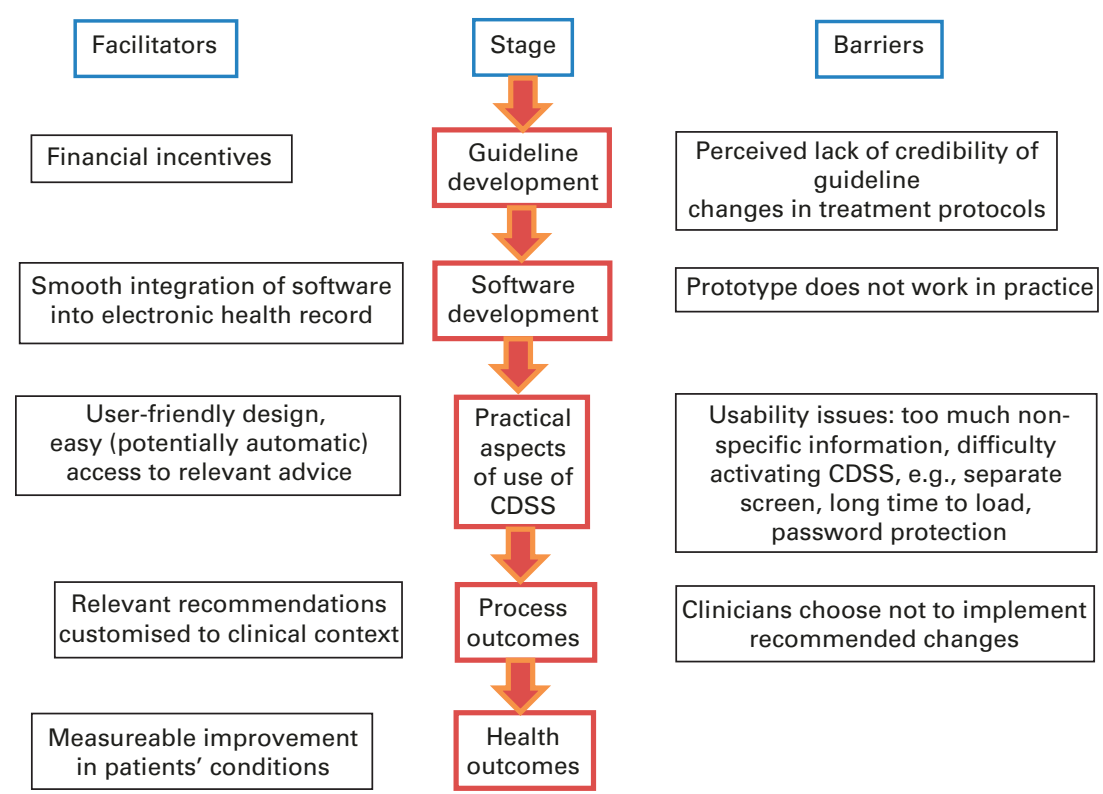

Figure 1. Theoretical model showing how a computer decision support system can improve asthma outcomes. 


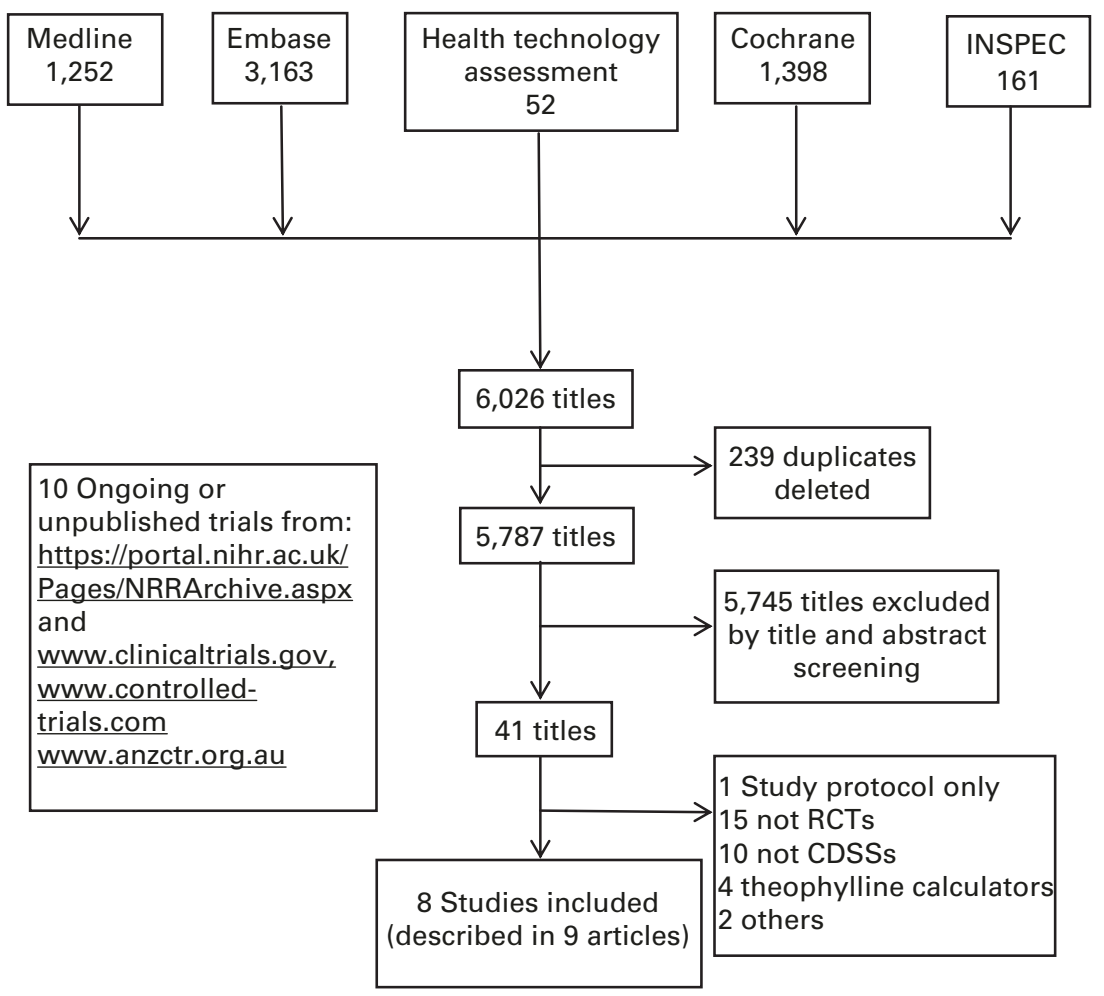

Figure 2. PRISMA flow diagram.

angina and cholesterol prescribing were unaware that their (usual care) asthma prescribing data were control data for the parallel asthma study.

Six of the systems were integrated into an electronic health record: ${ }^{20,22-24,26,27}$ one was partly integrated ${ }^{21}$ and one was a stand-alone system. ${ }^{25}$ Five of the studies ${ }^{20,21,23,26,27}$ explicitly reported that the system gave prescribing advice and reminders. One system concentrated solely on the prescribing of influenza vaccine for 'at-risk' children. ${ }^{27}$ Four studies were based on asthma management guidelines. ${ }^{21,25-27}$ One system included a complex risk prediction algorithm, ${ }^{25}$ and one system 'critiqued' the doctor's intended management plan and made recommendations. ${ }^{23}$

Risk of bias within studies

Table 2 lists the quality assessment: most studies were rated at high risk of bias. The study by Eccles et al. ${ }^{21}$ was rated at low risk of bias and that by Martens et al. ${ }^{24}$ at moderate risk of bias.

\section{Effectiveness of CDSSs}

The impact of CDSS on process, usage and clinical outcomes is detailed in Table 3. It was anticipated that usage and process outcomes would influence clinical outcomes as reflected in our model (Figure 1).

Practical aspects of CDSS use

In the study by Eccles et al., ${ }^{21}$ the median number of activations of the system per practice was zero. In that by Kuilboer et al., ${ }^{23}$ 10,863 visits generated 10,532 decision support comments, but the doctor waited for the critique only $22 \%$ of the time, and then read only a third of them. In Tierney et al.'s study, ${ }^{27}$ doctors complied with a third of the systems' suggestions. Bell et al. $^{20}$ reported that the CDSS was used $70 \%$ of the time. In the study by Fiks et al. ${ }^{22}$ the vaccine alerts were only active during $27 \%$ of visits.
Process outcomes

Changes in tests ordered. Eccles et al., ${ }^{21}$ McCowan et al. ${ }^{25}$ and Plaza et al. $^{26}$ all reported that the systems made no difference in the rates of ordering spirometry, X-rays, allergy tests or blood tests. Bell et $a .^{20}$ reported an increase in spirometry requests at intervention practices from 15 to $24 \%$, whereas there was a decrease at control practices from 8 to $1 \%$. In Kuilboer et al., ${ }^{23}$ peak expiratory flow rate and spirometry tests were ordered more often in the intervention group, in patients over 11 years of age. In a four-arm trial, Tierney et $a l^{27}$ reported that between 39 and $50 \%$ of patients received the suggestion to obtain pulmonary function tests.

Changes in treatments. Eccles et al., ${ }^{21}$ the only trial at low risk of bias, found no difference in asthma-related prescribing as a result of the intervention. Martens et al. $^{24}$ demonstrated an increase in the prescribing of inhaled corticosteroids to $44 \%$ of asthma patients (95\% confidence interval $(\mathrm{Cl}), 30-56 \%)$ in the intervention group, compared with $27 \%(95 \% \mathrm{Cl}, 14-47 \%)$ in the control group.

In the trial by Bell et al., ${ }^{20}$ there was a highly significant $(P=0.006)$ difference between the rate of prescribing inhaled corticosteroids in the subgroup of urban intervention practices compared with urban control practices. Urban and suburban practices were analysed separately in the cluster controlled trial because of marked baseline differences in patient population: the urban practices had more severe asthma.

Kuilboer et al. $^{23}$ demonstrated a significant reduction in the prescribing of cromoglyate in a post hoc analysis. Plaza et al. ${ }^{26}$ demonstrated a doubling of treatment conforming to guidelines, from 18 to $34 \%(P=0.02)$. Vaccination rates increased in both arms of the Fiks trial with no significant differences. ${ }^{22}$ McCowan et al. ${ }^{25}$ found no difference in asthma-related prescribing between the trial arms due to the intervention. Tierney et al. ${ }^{27}$ reported on treatment suggestions for both asthma and chronic obstructive pulmonary disease. For example, across the four arms of the Tierney trial, between 5 and $9 \%$ of patients received the suggest- 
Table 1. Characteristics of studies

\begin{tabular}{|c|c|c|c|c|c|c|}
\hline Author (country) & Study design & Participants and setting & $\begin{array}{l}\text { Age } \\
\text { (years) }\end{array}$ & Time scale & Intervention & Control \\
\hline Bell et al. ${ }^{20}$ (USA) & Cluster RCT & $\begin{array}{l}12 \text { clusters: } 12 \text { primary } \\
\text { care practices, } 19,450 \\
\text { patients }\end{array}$ & $0-18$ & $\begin{array}{l}12 \text { months } \\
6 \text { months prior to } \\
\text { study start } \\
\text { clinicians } \\
\text { participated in an } \\
\text { educational } \\
\text { programme, } \\
12 \text { months of } \\
\text { intervention }\end{array}$ & $\begin{array}{l}\text { CDSS embedded in an } \\
\text { electronic health record } \\
\text { (EHR) in the form of alerts } \\
\text { and reminders based on } \\
\text { expert asthma guidelines. } \\
\text { This included a data entry } \\
\text { tool, standardised } \\
\text { documentation for asthma } \\
\text { severity classification, } \\
\text { standardised drug and } \\
\text { spirometry order sets and } \\
\text { an asthma control plan. } \\
\text { There was also an } \\
\text { educational programme for } \\
\text { professionals. }\end{array}$ & $\begin{array}{l}\text { The control group } \\
\text { experienced educational } \\
\text { programme for } \\
\text { professionals. It also had } \\
\text { access to the data entry } \\
\text { and all documentation } \\
\text { tools but only passively, } \\
\text { without alerts and } \\
\text { reminders. }\end{array}$ \\
\hline Eccles et al. ${ }^{21}$ (UK) & $\begin{array}{l}\text { Cluster RCT with } \\
2 \times 2 \text { incomplete } \\
\text { block design }\end{array}$ & $\begin{array}{l}60 \text { clusters: } 60 \text { primary } \\
\text { care practices, } 1,129 \\
\text { patients }\end{array}$ & $\geqslant 18$ & $\begin{array}{l}24 \text { months } \\
12 \text { months } \\
\text { baseline period, } \\
12 \text { months } \\
\text { intervention }\end{array}$ & $\begin{array}{l}\text { CDSS offered suggestions } \\
\text { for management (including } \\
\text { prescribing) depending on } \\
\text { the chosen clinical scenario } \\
\text { and requested the entry of } \\
\text { relevant information. }\end{array}$ & $\begin{array}{l}\text { Controls received } \\
\text { intervention for angina, } \\
\text { while the asthma } \\
\text { intervention group was } \\
\text { the control from the } \\
\text { angina group as a } \\
\text { strategy to balance the } \\
\text { Hawthorne effect. }\end{array}$ \\
\hline Fiks et $a l^{22}$ (USA) & Cluster RCT & $\begin{array}{l}20 \text { clusters: } 20 \\
\text { practices, } 6,110 \\
\text { patients }\end{array}$ & $5-19$ & $\begin{array}{l}6 \text { months } \\
\text { All intervention }\end{array}$ & $\begin{array}{l}\text { CDSS was an EHR-based } \\
\text { influenza vaccination alert } \\
\text { system. Influenza vaccine } \\
\text { alerts appeared } \\
\text { prominently at the top of } \\
\text { the computer screen in } \\
\text { bold and highlighted text } \\
\text { whenever the electronic } \\
\text { health record was opened } \\
\text { for a study subject who was } \\
\text { due for this vaccine. Also a } \\
\text { link was provided to } \\
\text { simplify vaccine ordering. }\end{array}$ & $\begin{array}{l}\text { Described as routine } \\
\text { care. }\end{array}$ \\
\hline $\begin{array}{l}\text { Kuilboer et al. } \\
\text { (The Netherlands) }\end{array}$ & Cluster RCT & $\begin{array}{l}40 \text { clusters: } 32 \text { primary } \\
\text { care practices with a } \\
\text { total of } 40 \mathrm{GPs} \text {, each } \\
\text { control practice with a } \\
\text { mean of } 4,933 \text { control } \\
\text { and } 4,865 \text { intervention } \\
\text { patients }\end{array}$ & All & $\begin{array}{l}10 \text { months } \\
5 \text { months baseline } \\
\text { period, } 5 \text { months } \\
\text { intervention }\end{array}$ & $\begin{array}{l}\text { 'AsthmaCritic', the CDSS, } \\
\text { relied solely on the existing } \\
\text { data in the EHR. Once data } \\
\text { related to the visit was } \\
\text { entered, the system } \\
\text { evaluated whether the } \\
\text { patient had asthma or } \\
\text { COPD, reviewed the } \\
\text { physician's treatment of } \\
\text { asthma and COPD, and } \\
\text { generated feedback. In this } \\
\text { way, the doctor made the } \\
\text { decisions and the CDSS } \\
\text { 'critiqued' these decisions. }\end{array}$ & Described as usual care. \\
\hline $\begin{array}{l}\text { Martens et al. }{ }^{24,28} \\
\text { (The Netherlands) }\end{array}$ & $\begin{array}{l}\text { Cluster RCT with } \\
\text { an incomplete } \\
\text { block design }\end{array}$ & $\begin{array}{l}53 \text { clusters, } 14 \\
\text { practices with a } \\
\text { total of } 53 \mathrm{GPs}\end{array}$ & All & $\begin{array}{l}12 \text { months } \\
6 \text { months } \\
\text { intervention, } \\
6 \text { months data } \\
\text { collection }\end{array}$ & $\begin{array}{l}\text { CDSS was part of a } \\
\text { computer-reminder system } \\
\text { integrated into the EHR as a } \\
\text { prescribing module. When } \\
\text { the GP prescribed a drug } \\
\text { the decision support } \\
\text { system was activated and } \\
\text { provided information } \\
\text { specific to the patient (e.g., } \\
\text { age and gender) and the } \\
\text { prescribed drug. The GP } \\
\text { was obliged to enter a } \\
\text { diagnosis code which the } \\
\text { CDSS would check and use } \\
\text { to issue relevant reminders. }\end{array}$ & $\begin{array}{l}\text { One group that received } \\
\text { prescription reminders } \\
\text { for cholesterol-lowering } \\
\text { drugs served as controls } \\
\text { for the other group that } \\
\text { received CDSS for } \\
\text { antibiotics, asthma and } \\
\text { COPD, and vice versa. }\end{array}$ \\
\hline $\begin{array}{l}\text { McCowan et al. } \\
\text { (UK) }\end{array}$ & Cluster RCT & $\begin{array}{l}40 \text { clusters: } 40 \\
\text { practices, } 477 \text { patients }\end{array}$ & All & $\begin{array}{l}6 \text { months } \\
\text { No baseline data }\end{array}$ & $\begin{array}{l}\text { 'Asthma Crystal Byte' was a } \\
\text { stand-alone decision } \\
\text { support system with } \\
\text { management guidelines } \\
\text { for asthma that aimed to } \\
\text { improve the quality of the } \\
\text { consultation. It included } \\
\text { risk prediction software } \\
\text { and printed asthma } \\
\text { management plans. }\end{array}$ & $\begin{array}{l}\text { The control group had } \\
\text { no knowledge of the } \\
\text { intervention and had to } \\
\text { report parallel data on } \\
\text { the same number of } \\
\text { patients as were } \\
\text { recruited to the } \\
\text { intervention group. }\end{array}$ \\
\hline
\end{tabular}




\begin{tabular}{|c|c|c|c|c|c|c|}
\hline $\begin{array}{l}\text { Tierney et al. } \\
\text { (USA) }\end{array}$ & $\begin{array}{l}2 \times 2 \text { factorial } \\
\text { randomisation of } \\
\text { patients }\end{array}$ & $\begin{array}{l}4 \text { clusters: } 4 \text { hospital- } \\
\text { based academic } \\
\text { practices with } 25 \\
\text { faculty general } \\
\text { internists and over } 100 \\
\text { internal medicine } \\
\text { residents, } 1 \text { full-time } \\
\text { and } 9 \text { part-time } \\
\text { pharmacists, } 706 \\
\text { patients }\end{array}$ & $\geqslant 18$ & $\begin{array}{l}36 \text { months } \\
28 \text { months } \\
\text { recruitment and } \\
\text { baseline, } \\
8 \text { months } \\
\text { intervention }\end{array}$ & $\begin{array}{l}\text { CDSS generated care } \\
\text { suggestions based on } \\
\text { agreed guidelines. These } \\
\text { include performing } \\
\text { pulmonary function tests, } \\
\text { giving influenza and } \\
\text { pneumococcal } \\
\text { vaccinations, prescribing } \\
\text { advice and encouraging } \\
\text { smoking cessation. These } \\
\text { suggestions were } \\
\text { presented on doctors' } \\
\text { workstations or were } \\
\text { printed under a list of } \\
\text { active medications that } \\
\text { doctors received along with } \\
\text { the patient's paper chart } \\
\text { when he/she presented for } \\
\text { usual care. }\end{array}$ & $\begin{array}{l}\text { Care suggestions were } \\
\text { still generated by the } \\
\text { CDSS but were not } \\
\text { displayed to the } \\
\text { physician or pharmacists } \\
\text { caring for patients in the } \\
\text { control group. }\end{array}$ \\
\hline
\end{tabular}

Abbreviations: CDSS, computer decision support system; COPD, chronic obstructive pulmonary disease; GINA, The Global Initiative for Asthma; GP, general practitioner; RCT, randomised controlled trial.

ion to 'start inhaled corticosteroids.' However, only $11-30 \%$ of the physicians or pharmacists complied with this suggestion.

\section{Clinical outcomes}

Asthma symptoms. Three studies reported asthma symptoms. ${ }^{21,25,26}$ Eccles and coworkers ${ }^{30}$ reported that the CDSS had no effect on the validated Newcastle Asthma Symptoms Questionnaire (mean difference $-0.6(95 \% \mathrm{Cl},-2.1$ to 0.9$)$ ). ${ }^{21}$

Plaza et al. ${ }^{26}$ reported that asthma daytime symptoms, but not night-time symptoms, were significantly reduced in the intervention group compared with the control group (Wilcoxon $P<0.02$ ). McCowan et al. ${ }^{25}$ reported no significant differences in asthma symptoms between the intervention and control groups (odds ratio $0.3,95 \% \mathrm{Cl}, 0.03-3.3$ ), although this study was underpowered.

Asthma-related quality of life. Three studies reported asthmarelated quality of life. ${ }^{21,26,27}$ The study by Eccles et al., ${ }^{21}$ a trial at low risk of bias, reported no effect on the validated Asthma Quality of Life Questionnaire. ${ }^{31}$ Plaza and coworkers ${ }^{32}$ reported quality of life using the Spanish version of the St George's Respiratory Questionnaire and found significant improvement in all domains (activity $P=0.002$, symptoms $P=0.003$, impact $P=0.001){ }^{26}$ Tierney et $a .^{27}$ used two different quality-of-life scales, ${ }^{33,34}$ but found a significant result only in one subdomain, possibly due to multiple testing.

Frequency of asthma exacerbations. Two studies reported exacerbation rates. In the study by Plaza et al., ${ }^{26}$ exacerbation rates were not significantly different between the control and intervention groups: mean exacerbations, $1.3($ s.e. $)=1.2$ ) in the control group and 0.5 (s.e. $=0.3$ ) in the intervention group (Wilcoxon $P=0.2$ ). McCowan et al. ${ }^{25}$ reported that in the intervention group 12/147 patients had exacerbations compared with 57/330 in the control group: control patients were approximately twice as likely to experience an exacerbation as were intervention patients (odds ratio $0.4,95 \% \mathrm{Cl}, 0.2-0.9$, after adjustment for clustering). The denominators were different because of study dropouts.

Unscheduled health-care utilisation. McCowan et al. ${ }^{25}$ reported significantly fewer unscheduled general practitioner consultations in the intervention group in comparison with the control group (odds ratio $0.6,95 \% \mathrm{Cl}, 0.4-0.95$ ). Four studies reported no differences in the frequency of asthma-related visits to the general practitioner. ${ }^{20,22,23,26}$

Two studies reported no significant difference between the intervention and control groups in emergency department visits or hospitalisations. ${ }^{25,27}$ The absolute numbers were close to zero. 


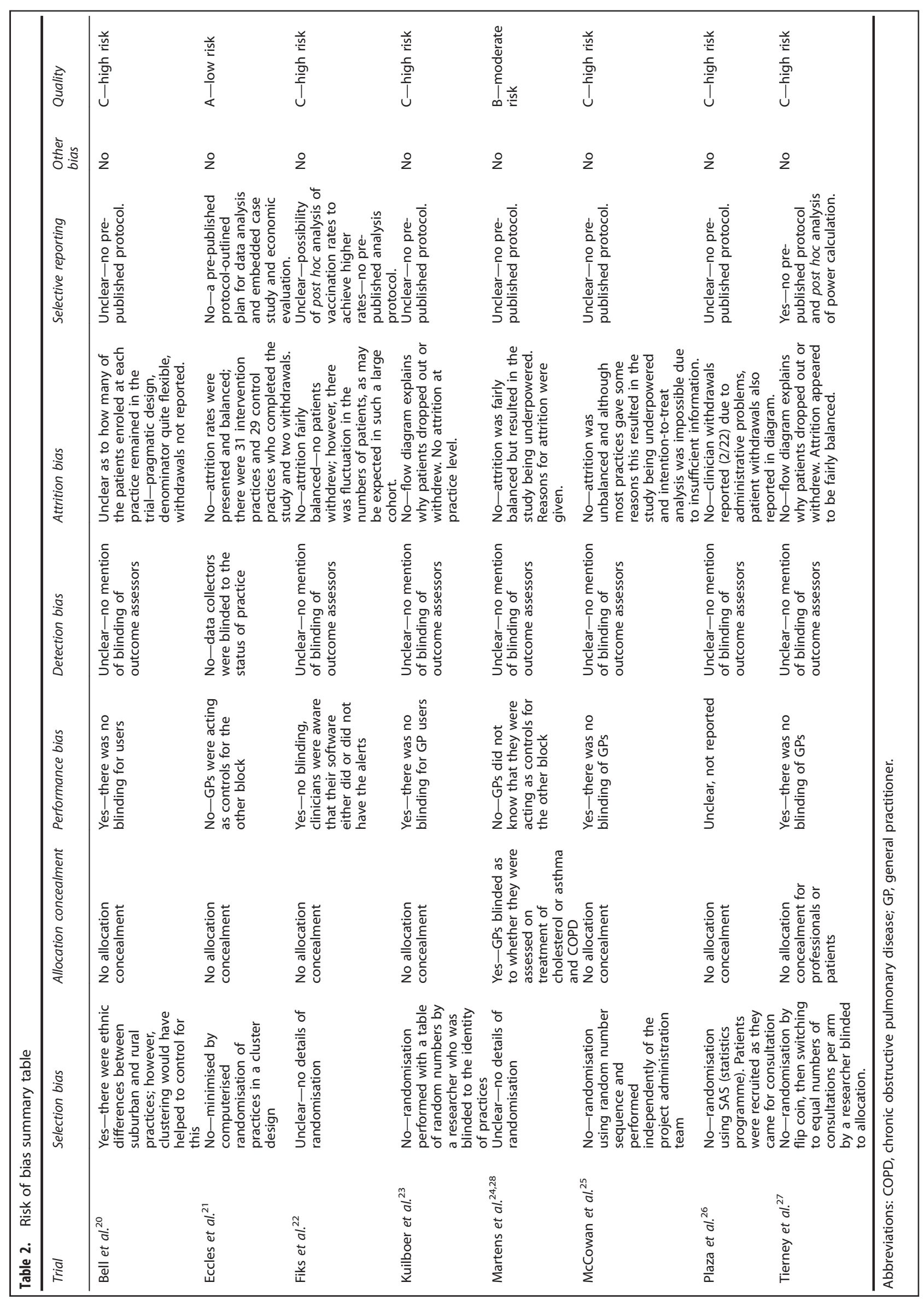




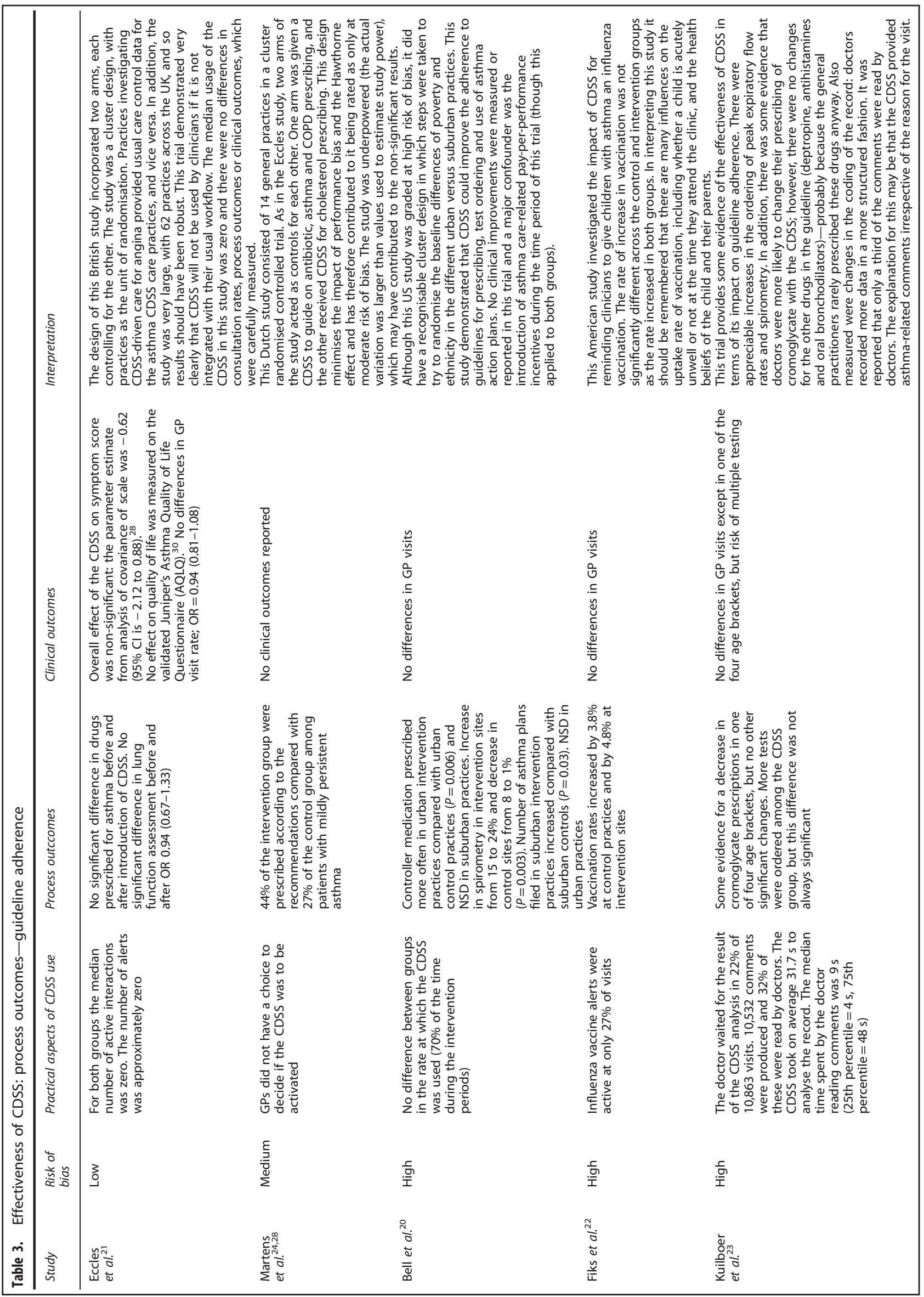




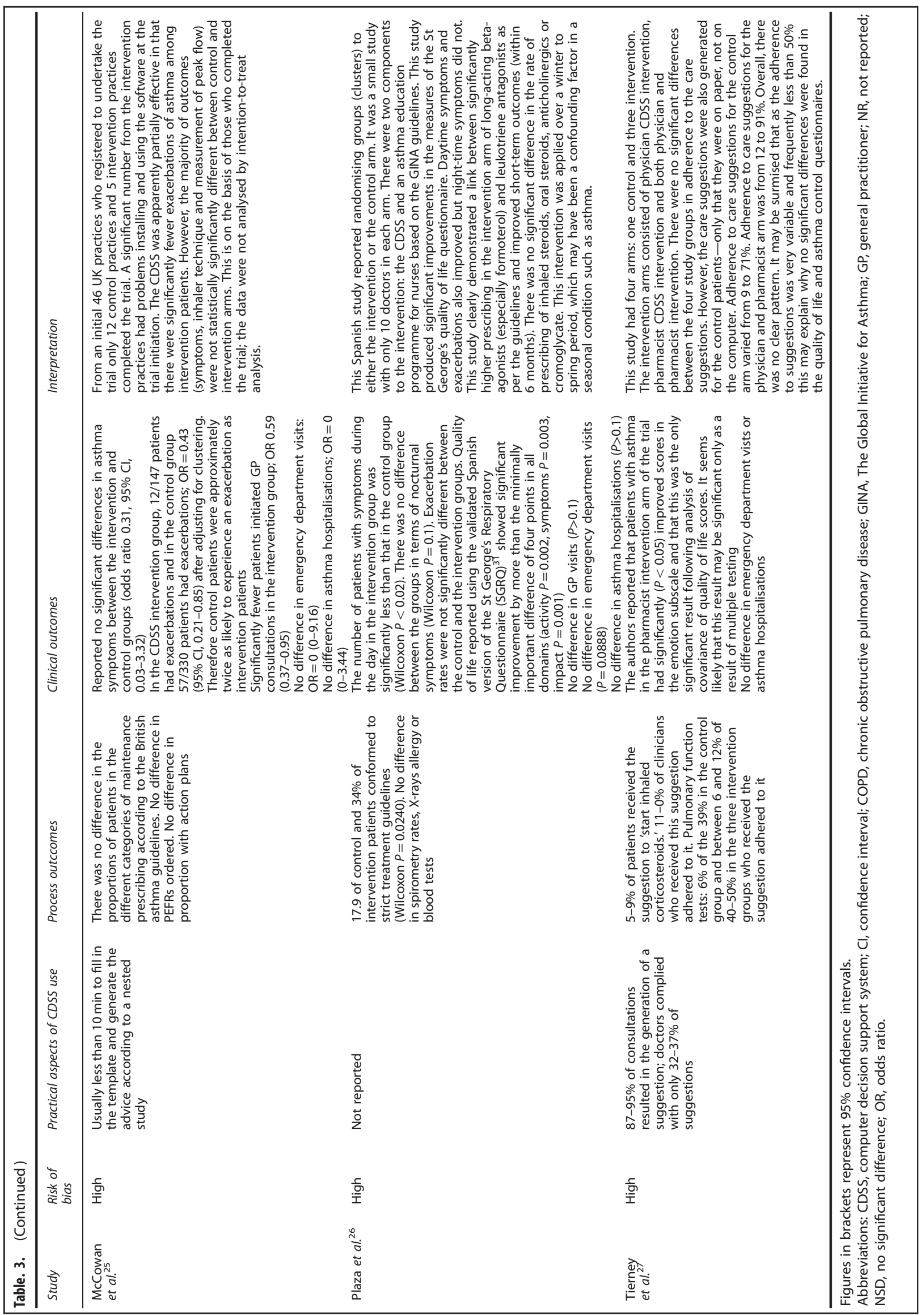




\section{DISCUSSION}

Main findings

We found eight relevant trials, four of which reported clinical measures of asthma control. ${ }^{21,25-27}$ The key finding was that CDSSs for health-care professionals were ineffective in improving patient outcomes because the systems were rarely used, ${ }^{21-23}$ and there was low compliance with the advice when it was issued. ${ }^{23,27}$ However, when systems are used, clinical outcomes can improve..$^{20,25}$

Strengths and limitations of this study

A strength of this review is its robust search strategy. We used the Cochrane-suggested terminology for asthma and randomised controlled trials, and drew on our eHealth research group's inclusive search terms for CDSS. ${ }^{35}$ Nevertheless, we may have missed some relevant studies, and the list of ongoing trials suggests that more evidence may be available in due course.

In contrast to the methodology used by the recent McMaster group series of reviews in which improvement was considered to have occurred if $>50 \%$ of the selected outcomes showed benefit, ${ }^{18,36-41}$ we report specific clinical, usage and process outcomes from each trial to explain why the systems were having an effect or not.

We did not perform a meta-analysis as populations and outcomes across trials were too heterogeneous. Descriptions of interventions were often poorly described, which may have limited our interpretation of the findings.

Interpretation of findings in relation to previously published work Our review focuses on asthma as a clinically important area for CDSSs. A crucial observation was that the systems were rarely used. ${ }^{1,21,42}$ Usage was not considered in the recent McMaster group's meta-regression, ${ }^{43}$ although this is clearly fundamental to understanding the reasons for lack of effect, and should be a crucial focus for development if systems are to improve patient outcomes above the $15-31 \%$ impact on outcomes reported by the McMaster group in a series of reviews. ${ }^{36-41}$ Usage rate of the systems should be a core standard for reporting trials of CDSSs.

The McMaster group's meta-regression explored the features of CDSSs associated with system 'effectiveness'. They found (1) stand-alone programs, (2) advice directed at both health-care practitioners and patients, (3) requiring users to enter an explanation for any overrides of system recommendations and (4) developers' involvement in trials to be associated with better patient outcomes. Poor integration (as in a stand-alone program), however, risks clinicians avoiding using the system as in Eccles et al. ${ }^{21}$ The issue, however, is complex as advice presented at the time of care does not always predict success, possibly because practitioners become overwhelmed by such integrated alerts that interrupt their workflow. ${ }^{43}$

Our recent analysis of recordings of general practice consultations emphasised the importance of the timing of alerts in the context of prescribing safety CDSSs. ${ }^{44}$ The practitioner, negotiating with the patient, makes decisions regarding drugs and management throughout the consultation when information about allergies, sensitivities, interactions and guideline recommendations might be useful. Provision of information during the final computer-based task of generating the prescription can frustrate clinicians, who then override the alerts. Integration with workflow requires a detailed study of the consultation process.

Implications for future research, policy and practice

A detailed description of the CDSS intervention under investigation is essential to providing insight into what promotes a wellused and effective system that can inform future development. Taxonomies and frameworks such as those described by Kawamoto et al., ${ }^{45}$ Garg et al. ${ }^{46}$ or Berlin et al. ${ }^{47}$ may provide a suitable basis for a full description. Future research should substantiate our theoretical model (Figure 1), which we suggest as a possible useful framework. In terms of the logical chain from usage to process outcomes to clinical outcomes, Bell et al. ${ }^{20}$ demonstrated that usage rates have an impact on process outcomes, and Plaza et al. ${ }^{26}$ demonstrated the impact of process outcomes on health outcomes. However, we feel that further research is required to evidence this model more thoroughly.

\section{Conclusions}

Our review suggests that current CDSSs are unlikely to result in improved outcomes in asthma because they are rarely used and the advice not followed. A key challenge in the future design of decision support systems lies in the better integration and alignment with professional workflows such that they are adopted into routine practice.

\section{ACKNOWLEDGEMENTS}

We acknowledge the support of Lisette van den Bemt (PM's supervisor from Radboud University Nijmegen).

\section{CONTRIBUTIONS}

PM and SM, with AS, HP and JCW, wrote the protocol and undertook the searches, selection of studies and extraction of data. All authors contributed to the interpretation of the findings. PM and SM wrote the initial draft of the paper. All the authors contributed to and have approved the final text. SM is the study guarantor.

\section{COMPETING INTERESTS}

All authors have completed the ICMJE uniform disclosure form (www.icmje.org/ coi_disclosure.pdf). AS serves on the World Health Organization's Health and Information Technology for Patient Safety Expert Working Groups and is an adviser to NHS Connecting for Health's Evaluation Programme. He is a consultant to ALK and Phadia, and has received support from Napp, Pfizer and Cheisi for research advice. AS is Joint Editor-in-Chief of, and HP is an Associate editor of, the PCRJ; neither were involved in the editorial review of, nor the decision to publish, this article. HP has spoken for AstraZeneca, Boehringer Ingelheim, Chiesi, GlaxoSmithKline, Pfizer and Teva and undertaken advisory group work for Chiesi. The remaining authors declare no conflict of interest.

\section{FUNDING}

There was no specific funding for this research. HP was supported by a Primary Care Research Career Award from the Chief Scientist's Office of the Scottish Government at the time of work on this review.

\section{REFERENCES}

1 Global Initiative for Asthma. The global strategy for asthma management and prevention, 2012. Available from http://www.ginasthma.org (accessed September 2013).

2 Patel S, Jarvelin M, Little M. Systematic review of worldwide variations of the prevalence of wheezing symptoms in children. Environ Health 2008; 7: 57.

3 Beasley R for the International Study of Asthma and Allergies in Childhood (ISAAC) Steering Committee. Worldwide variation in prevalence of symptoms of asthma, allergic rhinoconjunctivitis, and atopic eczema. Lancet 1998; 351: 1225-1232.

4 Anandan C, Nurmatov U, van Schayck OC, Sheikh A. Is the prevalence of asthma declining? Systematic review of epidemiological studies. Allergy 2009; 65: $152-167$.

5 Gupta R, Sheikh A, Strachan DP, Anderson HR. Burden of allergic disease in the UK: secondary analyses of national databases. Clin Exp Allergy 2004; 34: 520-526.

6 National Heart, Lung and Blood Institute. Guidelines for the diagnosis and management of asthma, 2007. Available from http://www.nhlbi.nih.gov/guidelines/ asthma/ (accessed September 2013). 
7 British Thoracic Society/Scottish Intercollegiate Guideline Network. British guideline on the management of asthma, 2012. Available from http://www.sign ac.uk/guidelines/fulltext/101/index.html (accessed September 2013)

8 Canadian Thoracic Society. CTS 2012 Guideline Update: diagnosis and management of asthma in preschoolers, children and adults. Available from http://www ncbi.nlm.nih.gov/pmc/articles/PMC3373283 (accessed September 2013).

9 Rabe KF, Adachi M, Lai CKW, Soriano JB, Vermeire PA, Weiss KB et al. Worldwide severity and control of asthma in children and adults: the global asthma insights and reality surveys. J Allergy Clin Immunol 2004; 114: 40-47.

10 Haughney J, Barnes G, Partridge M, Cleland J. The Living \& Breathing study: a study of patients' views of asthma and its treatment. Prim Care Resp J 2004; 13 28-35.

11 Stallberg B, Lisspers K, Hasselgren M, Janson C, Johansson G, Svardsudd K. Asthma control in primary care in Sweden: a comparison between 2001 and 2005. Prim Care Respir J 2009; 18: 279-286.

12 Cabana MD, Rand CS, Powe NR, Wu AW, Abboud PC, Rubin HR. Why don't physicians follow clinical practice guidelines? A framework for improvement. JAMA 1999; 282: 1458-1465.

13 Wiener-Oglilvie S, Pinnock H, Huby G, Sheikh A, Partridge MR, Gillies J. Do practices comply with key recommendations of the British Asthma Guideline? If not why not? Prim Care Respir J 2007; 16: 369-377.

14 Robertson A, Cresswell K, Takian A, Petrakaki D, Crowe S, Cornford T et al. Implementation and adoption of nationwide electronic health records in secondary care in England: qualitative analysis of interim results from a prospective national evaluation. BMJ 2010; 341: c4564.

15 Sheikh A, Cornford T, Barber N, Avery A, Takian A, Lichtner V et al. Implementation and adoption of nationwide electronic health records in secondary care in England: final qualitative results from prospective national evaluation in "early adopter" hospitals. BMJ 2011; 343: d6054.

16 Higgins J, Green S. Cochrane Handbook for Systematic Reviews of Interventions, Version, 5.1.0 edn. The Cochrane Collaboration, 2011. http://www.cochrane.org/ training/cochrane-handbook (accessed September 2013).

17 Wyatt J, Spiegelhalter D. Field trials of medical decision-aids: potential problems and solutions. Proc Annu Symp Comput Appl Med Care 1991, 3-7.

18 Haynes RB, Wilczynski NLfor the CDSS SystematicReviewTeam. Effects of computerized clinical decision support systems on practitioner performance and patient outcomes: methods of a decision-maker-researcher partnership systematic review. Implement Sci 2010; 5: 12.

19 Reddel HK, Taylor DR, Bateman ED, Boulet LP, Boushey HA, Busse WW et al. An Official American Thoracic Society/European Respiratory Society Statement: asthma control and exacerbations: standardizing endpoints for clinical asthma trials and clinical practice. Am J Respir Crit Care Med 2009; 180: 59-99.

20 Bell LM, Grundmeier R, Localio R, Zorc J, Fiks AG, Zhang X et al. Electronic health record-based decision support to improve asthma care: a cluster-randomized trial. Pediatrics 2010; 125: e770-e777.

21 Eccles M, McColl E, Steen N, Rousseau N, Grimshaw J, Parkin D et al. Effect of computerised evidence based guidelines on management of asthma and angina in adults in primary care: cluster randomised controlled trial. $B M J$ 2002; 325: 941.

22 Fiks AG, Hunter KF, Localio AR, Grundmeier RW, Bryant-Stephens T, Luberti AA et al. Impact of electronic health record-based alerts on influenza vaccination for children with asthma. Pediatrics 2009; 124: 159-169.

23 Kuilboer MM, van Wijk MA, Mosseveld M, van der Does E, de Jongste JC, Overbeek SE et al. Computed critiquing integrated into daily clinical practice affects physicians' behavior - a randomized clinical trial with AsthmaCritic Methods Inf Me 2006; 45: 447-454.

24 Martens JD, van der Weijden T, Severens JL, de Clercq PA, de Bruijn DP, Kester AD et al. The effect of computer reminders on GPs' prescribing behaviour: a clusterrandomised trial. Int J Med Inform 2007; 76: S403-S416.

25 McCowan C, Neville RG, Ricketts IW, Warner FC, Hoskins G, Thomas GE. Lessons from a randomized controlled trial designed to evaluate computer decision support software to improve the management of asthma. Inform Health Social Care 2001; 26: 191-201.

26 Plaza V, Cobos A, Ignacio-Garcia JM, Molina J, Bergoñón S, García-Alonso F et al. Cost-effectiveness of an intervention based on the Global INitiative for Asthma (GINA) recommendations using a computerized clinical decision support system a physicians randomized trial [Spanish]. Med Clin 2005; 124: 201-206.

27 Tierney WM, Overhage JM, Murray MD, Harris LE, Zhou XH, Eckert GJ et al. Can computer-generated evidence-based care suggestions enhance evidence-based management of asthma and chronic obstructive pulmonary disease? A randomized controlled trial. Health Services Res 2005; 40: 477-497.

28 Martens JD, van der Aa A, Panis B, van der Weijden T, Winkens RA, Severens JL. Design and evaluation of a computer reminder system to improve prescribing behaviour of GPs. Stud Health Technol Inform 2006; 124: 617-623.
29 Durieux P, Trinquart L, Colombet I, Niès J, Walton R, Rajeswaran A et al. Computerized advice on drug dosage to improve prescribing practice. Cochrane Database Syst Rev 2008, CD002894. doi:10.1002/14651858.CD002894.pub2.

30 Steen N, Hutchinson A, McColl E, Eccles MP, Hewison J, Meadows KA et al. Development of a symptom based outcome measure for asthma. BMJ 1994; 309: 1065-1068.

31 Juniper EF, Buist AS, Cox FM, Ferrie PJ, King DR. Validation of a standardized version of the Asthma Quality of Life Questionnaire. Chest 1999; 115: 1265-1270.

32 Ferrer M, Alonso J, Prieto L, Plaza V, Monsó E, Marrades R et al. Valididty and reliability of the St George's Respiratory Questionnaire after adaptation to a different language aand culture: the Spanish example. Eur Respir J 1996; 9 : $1160-1166$

33 Guyatt GH, Berman LB, Townsend M, Pugsley WO, Chanbers LW. A measure of quality of life for clinical trials in chronic lung disease. Thorax 1987; 42: 773-778.

34 Juniper E, Guyatt GH, Ferrie PJ, Griffith LE. Measuring quality of life in asthma. Am Rev Resp Dis 1993; 147: 832-838.

35 Car J, Black A, Anandan C, Cresswell K, Pagliari C, McKinstry B et al., The Impact of eHealth on the Quality \& Safety of Healthcare. Connecting for Health Evaluation Programme 001 Report. University of Birmingham: Birmingham, UK, 2011.

36 Roshanov PS, Misra S, Gerstein HC, Garg AX, Sebaldt RJ, Mackay JA et al., for the CCDSS SystematicReviewTeam. Computerized clinical decision support systems for chronic disease management: a decision-maker-researcher partnership systematic review. Implement Sci 2011; 6: 92.

37 Sahota N, Lloyd R, Ramakrishna A, Mackay JA, Prorok JC, Weise-Kelly L et al., for the CCDSS SystematicReviewTeam.. Computerized clinical decision support systems for acute care management: a decision-maker-researcher partnership systematic review of effects on process of care and patient outcomes. Implement Sci 2011; 6: 91

38 Nieuwlaat R, Connolly SJ, Mackay JA, Weise-Kelly L, Navarro T, Wilczynski NL et al., for the CCDSS SystematicReviewTeam. Computerized clinical decision support systems for therapeutic drug monitoring and dosing: a decision-maker-researcher partnership systematic review. Implement Sci 2011; 6: 90.

39 Hemens BJ, Holbrook A, Tonkin M, Mackay JA, Weise-Kelly L, Navarro T et al., for the CCDSS SystematicReviewTeam. Computerized clinical decision support systems for drug prescribing and management: a decision-maker-researcher partnership systematic review. Implement Sci 2011; 6: 89.

40 Roshanov PS, You JJ, Dhaliwal J, Koff D, Mackay JA, Weise-Kelly L et al., for the CCDSS SystematicReviewTeam. Can computerized clinical decision support systems improve practitioners' diagnostic test ordering behavior? A decision-makerresearcher partnership systematic review. Implement Sci 2011; 6: 88

41 Souza NM, Sebaldt RJ, Mackay JA, Prorok JC, Weise-Kelly L, Navarro T et al., for the CCDSS SystematicReviewTeam. Computerized clinical decision support systems for primary preventive care: a decision-maker-researcher partnership systematic review of effects on process of care and patient outcomes. Implement Sci 2011; 6 : 87.

42 Ryan D, Price D, Musgrave SD, Malhotra S, Lee AJ, Ayansina D et al. Clinical and cost effectiveness of mobile phone supported self monitoring of asthma: multicentre randomised controlled trial. BMJ 2012; 344: e1756.

43 Roshanov PS, Fernandes N, Wilczynski JM, Hemens BJ, You JJ, Handler SM et al. Features of effective computerised clinical decision support systems: metaregression of 162 randomised trials. BMJ 2013; 346: f657.

44 Hayward J, Thomson F, Milne H, Buckingham S, Sheikh A, Fernando B et al. 'Too much, too late': mixed methods multi-channel video recording study of computerized decision support systems and GP prescribing. J Am Med Inform Assoc 2013; 7: 7.

45 Kawamoto K, Houlihan CA, Balas EA, Lobach DF. Improving clinical practice using clinical decision support systems: a systematic review of trials to identify features critical to success. BMJ 2005; 330: 765-768.

46 Garg AX, Adhikari NKJ, McDonald H, Rosas-Arellano MP, Devereaux PJ, Beyene J et al. Effects of computerized clinical decision support systems on practitioner performance and patient outcomes: a systematic review. JAMA 2005; 293: 1223-1238.

47 Berlin A, Sorani M, Sim I. A taxonomic description of computer-based clinical decision support systems. J Biomed Inform 2006; 39: 656-667.

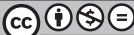

This work is licensed under a Creative Commons AttributionNonCommercial-NoDerivatives 4.0 International License. The images or other third party material in this article are included in the article's Creative Commons license, unless indicated otherwise in the credit line; if the material is not included under the Creative Commons license, users will need to obtain permission from the license holder to reproduce the material. To view a copy of this license, visit http:// creativecommons.org/licenses/by-nc-nd/4.0/ 